\title{
THE IMPACT OF SCHOOL DESEGREGATION ON THE SELF-EVALUATION AND ACHIEVEMENT ORIENTATION OF MINORITY CHILDREN
}

\author{
EDGAR G. EPPS*
}

\section{INTRODUCTION}

This paper focuses on several aspects of a child's personality which are thought to have some effect on academic achievement and examines what can be discerned from the research concerning the impact of desegregation on these personality characteristics. It also considers evidence on personality differences related to ethnic and socioeconomic status differences that can help clarify the processes involved in the development or shaping of personality orientations, regardless of whether the research involved dealt with desegregation. The paper examines three areas of personality: self-evaluation and racial identity; self-esteem and self-concept; and motivation for achievement. The discussion of each area begins with an examination of the general conceptual and methodological issues and then focuses on the impact of desegregation on that aspect of personality. This analysis is primarily concerned with black-white differences, since there is almost no research dealing with the effects of desegregation on the personality of other racial and ethnic groups.

A series of questions recurs throughout the paper. First, and most basic, do we understand what the phenomenon we are observing is? Second, how certain are we that differences between blacks and whites are related to personality rather than to home environment or school environment? Third, how can we be sure that desegregation has an impact if we do not fully understand the developmental processes it affects? Finally, what do the research results suggest for educational policymakers?

\section{Self-Evaluation and Racial Identity}

\section{A. Research on Racial Identity}

Research in this area investigates the extent to which black children or other minority children develop racial self-hatred, a low sense of self-worth,

* Professor of Education, The University of Chicago. 
preference for the dominant group, or dislike for their own group as a result of growing up in a racist society. The research usually involves asking children to choose pictures or dolls that are "like me" or "unlike me"; to select the "good child," the "pretty child," or the child each would like to play with or work with. Inferences about children's self-images and racial self-identity are then made from these choices. Consequently, the results are adult attributions of feelings and motives to children rather than direct assessments of children's feelings about themselves.

Recent reviews of research on racial identity indicate that although a considerable amount of work is being done, this is an area beset with many methodological and conceptual problems that make it difficult to draw firm conclusions. ${ }^{1}$ There are methodological disputes about the use of different instruments and procedures, the age, sex, and status composition of samples, and the appropriateness and relevance of various social contexts, laboratories, playgrounds, schools, different geographic regions, and different desegregation status. Generalizing from the data is difficult. The conceptual problems, which will be discussed in more detail at various stages in the paper, include inconsistent uses of the terms "self-esteem" and "self-concept," and the need to clarify the relevance of research data on a child's experience in the classroom to studies on the effects of desegregation.

Another conceptual problem is the extent to which a child's acquisition of racial attitudes is a developmental process the character of which changes as the child grows older. Though her research supports earlier studies that indicate that racial cues are well developed by the age of three, ${ }^{2} \mathrm{Katz}$, on the basis of her own research and her review of a wide range of studies in this area, concludes that a less truncated developmental pattern can be discerned. She delineates the following model:

There appear to be at least eight overlapping, but separable, steps in the developmental sequence of racial attitude acquisition, which span approximately ten years of the child's life. These include the following: (1) early observation of racial cues, (2) formation of rudimentary concepts, (3) conceptual differentiation, (4) recognition of the irrevocability of cues, (5) consolidation of group concepts, (6) perceptual elaboration, (7) cognitive elaboration, and (8) attitude crystallization. ${ }^{3}$

1. See generally Banks \& Rompf, Evaluative Bias and Preference in Black and White Children, 44 Child Development 776 (1973); Banks, White Preference in Blacks: A Paradigm in Search of a Phenomenon, 83 Psych. Bull. 1179 (1976); M. E. B. Spencer, The Social-Cognitive and Personality Development of the Black Preschool Child: An Exploratory Study of Developmental Process (December 1976) (unpublished doctoral dissertation, The University of Chicago); $M$. Weinberg, Minority Students: A Research Appraisal (1977).

2. Katz, The Acquisition of Racial Attitudes in Children, in Towards The Elimination of Racism 125,145 (P. Katz ed. 1976).

3. Id. at 148 . 
The pattern Katz describes emphasizes that younger children's racial attitudes are not yet crystallized. "Continuing research focus on the preschool years may well have obscured the importance of the early grade-school years as focal points in attitude transition," Katz asserts- "evidence suggests that attitudes continue to develop and differentiate during the middle childhood years."

Studies of children below grade four must take such a developmental pattern into account and be extremely cautious about attributing lasting personality effects to outcomes of studies of young children. The younger the children studied, the greater the need for cautious interpretation of the results.

A great deal of research-some from as far back as the early 1940s-has compared the racial preferences of white and black children. In 1975 Winnick and Taylor studied sixty black and sixty white three- to eight-year-old children in South Carolina who were grouped by age and socioeconomic status. ${ }^{5}$ The public schools in the area were desegregated, but the report did not make clear whether the preschool children had been exposed to interracial situations. This study included a doll selection test, which yielded some interesting results. The majority of black children (64 percent) showed preference for their own race. This was almost double the number (about one-third) of the black children who had demonstrated a preference for their own race in a similar doll study published by Clark and Clark in $1947 .^{6}$

Winnick and Taylor also found in their 1975 study that white children chose dolls of their own race more consistently than did black children, and that among both races a child's consistency of performance increased with his or her age. These results were not affected by the sex, socioeconomic status, or race of the experimenter. ${ }^{7}$ However, Katz obtained different results with respect to the impact of the race of the experimenter. She found that, among younger children, the presence of an experimenter of the opposite race increased the salience of racial cues, increasing the children's tendencies to identify with their own race. ${ }^{8}$ However, Katz cautions that analyses of the influence of the race of the experimenter that focus only on the objective characteristics of these adults will only obscure the mechanism by which children acquire racial attitudes. She stresses that this is a complex effect-that there should be more theoretical work as well as experimentation on whether

\footnotetext{
4. Id. at 150 .

5. Winnick \& Taylor, Racial Preference-36 Years Later, 102 J. Soc. Psych. 157 (1977).

6. Id. at 158; Clark \& Clark, Racial Identification and Preference in Negro Children, in Readincs In Social Psychology 169, 175 (Society for the Psychological Study of Social Issues ed. 1947).

7. Winnick \& Taylor, supra note 5. at 158.

8. Katz. supra note 2, at 141.
} 
there is a relationship between the racial attitudes of children and the different reinforcement effects of different adults. ${ }^{9}$

Other research in the area of racial identity has also questioned whether a researcher's results could vary depending on the selection task he or she asked the child to do. Banks and Rompf studied thirty-four white and thirtyfour black middle-class children of both sexes who ranged from six to eight years of age. ${ }^{10}$ These children lived in segregated neighborhoods and were studied while school was closed for the summer. Children were required to dispense rewards to black or white adults for success at playing a game. Their task was then changed to choosing the winner of the game. The outcome presented was sufficiently ambiguous that children could use some subjective judgment. Results indicated that black children discriminated in racial preference according to the task involved, while white children did not. When they were dispensing rewards (which the authors classed as a quantitative task), the black children favored the white players. In contrast, when given a different assignment-choosing the winner, a qualitative task-the black children were more likely to choose the black player. White children showed a preference for their own race in both tasks. The race of the experimenter did not affect the results. These results provide clear evidence that these children did not feel global self-hatred ${ }^{11}$ and that their attitudes towards themselves in relation to their racial identity shifted depending on the circumstances in which they found themselves. The authors note:

Within an experimental design where social and task structure variables were manipulated, preference behavior on the part of black children was found to be highly variable. If a generalized internal process like self-concept were motivating preference behavior, such variance could not be anticipated or explained. To the extent that such behavior covaries with experimentally controllable factors, it is extremely difficult to attribute it to internal traits. ${ }^{12}$

In other words, the results indicate that while racial preference patterns may have changed among black children in recent years, they can still be induced to show white preferences depending upon the tasks required. This study suggests that the nature of the tasks and assessments must be considered, as well as the contexts in which the effort takes place.

In a later paper, Banks raises an even more basic conceptual issue. He questions the validity of trying to determine blacks' self-concepts by comparing their choices with those of whites. ${ }^{13}$ The appropriate research question, he contends, is the extent to which choices made by black children differ due to chance. Using this criterion, his analysis of the results of the most prominent

9. Id. at 133 .

10. See Banks \& Rompf, supra note 1, at 777.

11. Id, at 781 .

12. Id. at 782 .

13. Banks, supra note 1 . 
studies of preference behavior in blacks indicated that in only 6 percent of the experiments did black children demonstrate white preference. "The predominant pattern of black choice responses has been at a chance level," he asserts. ${ }^{14}$ Banks concludes that since the phenomenon has not been demonstrated, efforts to refine the research design are probably misdirected.

Spencer points out that few researchers give adequate consideration to the developmental issues regarding concept acquisition (self, other, race, ethnicity). ${ }^{15}$ In her research, Spencer found a significant nonlinear relationship between racial attitudes and self-concept. Specifically, 80 percent of the four-and five-year-olds were found to have both "Majority Culture Preference Racial Attitudes" and positive self-concepts. ${ }^{16}$ She states:

Previous to this research, virtually all research on the personality disposition of Black Americans has accepted the assumption that given the racial preferential behavior of black children (i.e., doll choice, racial statements, etc.), blacks must necessarily suffer from low self-esteem or negative self-concepts. Generally, this inference has been made without assessing self-concept and racial attitudes in the same population. ${ }^{17}$

The research demonstrates clearly that young black children do not internalize the negative societal evaluation of blacks, even as they learn that blacks are devalued in society. The work of Williams and Morland also indicates that black children become aware of the negative societal images of blackness at an early age. However, these researchers also found that older black youths (junior high school age and older) evaluate black images more positively than white images. ${ }^{18}$ This suggests that an eighth grader, because he is older, may have a different concept of social identity than would a first grader. On the other hand, since the data on the older black youths was gathered in recent years, in the wake of the black identity movement, historical forces may also have influenced the results.

\section{B. Desegregation and Racial Identity}

The most extensive study of racial identity in the context of desegregation was conducted in Riverside, California. That study included several measures of "adjustment." 19 The two discussed in this section of the article are selfattitude and ethnic identification. Self-attitude was measured by two agegraded tests designed to assess emotional health. The authors suggest that these measures may be considered rough indices of a child's self-confidence,

\footnotetext{
14. Id. at 1185 .

15. M. E. B. Spencer, supra note 1 .

16. Id. at 172 .

17. Id. at 200.

18. J. Williams \& J. Morland, Race, Color, and the Young Child 131 (1976).

19. Goodchilds, Green, \& Bikson. The School Experience and Adjustment, in SCHOOL Desegregation: A Long-Term Study (H. Gerard \& N. Miller eds. 1975) 152-56.
} 
his attitude toward himself, or self-esteem. The measure for the younger children involved a card sorting task that yielded a total score and three subscores. The measure for the older children required the child to indicate whether or not he or she would like to be an imaginary child and whether the imaginary child is or is not "like me." This was a forty item self-report measure.

The Riverside study found that the younger Anglo, black, and Mexican American children were equally happy with themselves in the school setting. The Anglo students had significantly higher overall "happiness scores" (selfattitude), however, and higher scores for the play and home settings. Three years later, after desegregation had taken place, these results had not changed. Among the older children, there were even fewer differences. The only significant result was one interaction, which suggests that "for children aged 10 and up-the black male child may have an unusually high and the black female child an unusually low satisfaction-with-self-attitude." ${ }^{20}$ There was also a suggestion that for the older black children a favorable self-attitude is associated with higher academic achievement.

Photographic assessment of ethnic identity, a technique that uses photographs of male and female black, Mexican American, and Anglo children, was also used in the Riverside study. The clearest result, as one would expect, is that children in all of the groups were most likely to choose a same-racesame-sex picture as "most like me." This pattern was more pronounced after two years of desegregation, with fewer minority group children choosing a picture of an Anglo child in the third year.

Instances of minority group children choosing to identify with other groups might be attributed to the ambiguity of color cues or ethnic cues in the pictures for some black and Mexican American children because of the broad range of physical characteristics among both of these groups-some of these children would have features that resemble Anglo characteristics.

The Riverside study indicated that a child's ethnic identity and self-attitude are not closely linked: when data measuring these two factors were analyzed together, they showed no significant relationship. This is a point well worth considering when evaluating research on ethnic identity. Although few studies have attempted to relate self-esteem to racial preference and associated attitudes, where this has been attempted, researchers usually have found the relationship of the measures to be extremely weak. ${ }^{21}$ Most studies measure racial awareness, racial preference, racial attitudes, or racial identification and

20. Id. at 162 .

21. H. P. McAdoo. The Development of Self-Concept and Race Attitudes in Black Children: A Longitudinal Study, in Report of the Third Conference on Empirical Research in Black Psychology 48, 49 (December 1977) (report for Nat'l Inst. of Educ., Dep't of Health, Educ., \& Welfare) (ERIC Document No. 148 944). 
then make inferences about self-concept or self-image. It is difficult, however, to reach any conclusions about the impact of desegregation on racial identity on the basis of subjective analyses using inferences to discern causation.

McAdoo studied the development of self-esteem and attitudes on race in Mississippi, Michigan, and Washington, D.C. over a period of five years. ${ }^{22}$ She found that a child's preference for his or her own race increased after attending an interracial school. The Mississippi sample was drawn from an all-black community, the Washington, D.C. sample from a predominantly black home and school setting with limited interracial contacts, and the Michigan sample from a residentially segregated community whose children attended biracial schools.

At the preschool level (the first testing) the Mississippi children were most accurate in their racial identification of pictures, significantly more so than either the Michigan or Washington children, with the Washington children being least accurate. The Michigan and Mississippi samples did not differ in orientation toward other races; the Washington sample was more oriented toward other races than were the other two samples.

Over time:some changes were recorded. While racial attitudes in the Washington sample did not change after one year, the self-concept scores increased; although these were still slightly lower than the scores of the Mississippi and Michigan groups. In the five year follow-up in Michigan and Mississippi, both groups became less oriented toward other groups, with Michigan students exhibiting less of this white preference than Mississippi students. ${ }^{23}$ At this testing, children were asked, "What type of person do most people in America think is best?" They were given the choices of black, Jewish, white Protestant, and white Catholic. The question was repeated until all groups had been ranked. Only the black Michigan children (those in an interracial setting) ranked blacks higher than other ethnic groups. At the preschool level, the Mississippi children had higher self-esteem than that of the Michigan and Washington children. However, by age ten the self-concept of the Michigan children had increased to the high level of the Mississippi children.

How do McAdoo's results relate to desegregation? The segregated Mississippi and Washington samples differed significantly on both self-concept and racial attitudes. The desegregated Michigan sample was least white oriented, while the Washington sample was most white oriented. Orientation toward whites among the segregated Mississippi sample was at a level between that of the Michigan and Washington samples.

While the community setting, the age of the children, and the length of the follow-up period were all confounding factors, it seems clear that only the

22. Id.

23. Id. at $\mathbf{5 9}$. 
desegregated Michigan sample exhibited relative high own-group preference, as well as positive self-esteem at age ten. Thus, while early experience with desegregated schooling may have depressed self-concept scores and encouraged preference for other groups and confusion about racial identity, after five years of desegregated schooling these Michigan children had equaled the Mississippi children in self-esteem and surpassed them in acquisition of problack racial attitudes. In contrast, the five-year experience in an all-black setting had maintained the initial high self-concepts of the Mississippi children, but had not resulted in problack racial attitudes. This study, like that of Miller and Gerard, ${ }^{24}$ seems to support the generalization that preference for one's own race increases with experience in interracial schools. In assessing the results of the group of studies relating desegregation and self-concept, the overall historical context must also be considered. Weinberg has observed, "Racial self-awareness has apparently increased sharply, both in the North and in the South. Racial self-acceptance has also undoubtedly risen. But the degree of such a rise has been overstated." 25

In summarizing this section, several points are worth mentioning. First, because of the numerous conceptual and methodological issues that still remain to be resolved in research on ethnic identity and self-evaluation, it is very difficult to make meaningful generalizations from studies of the effects of desegregation on these types of self-attitudes. Better research designs may resolve some of the methodological problems, but conceptual problems such as those described by Banks ${ }^{26}$ will be more difficult to overcome. What can be gleaned from these studies is that careful attention must be given to the complex developmental factors involved in the way children acquire racial concepts, conceptualize them at different ages, and relate these concepts to their own sense of personal worth and group identity. It seems clear that the social context is important, in that geographical location and the amount (and probably the type) of interracial experience affect the way children perceive race and its meaning for them. However, the evidence available does suggest that, if anything, desegregation tends to strengthen racial self-identification and preferences for one's own race among black children by the time they have reached ten years of age. Even more important, however, is the evidence that racial self-identity and racial preference measures are not related to selfconcept as measured by self-report techniques.

24. Goodchilds, Green, \& Bikson, supra note 19 , at 163.

25. M. WEINBERG, supra note 1, at 169.

26. Banks, supra note 1 , at 1179 . 


\section{Self-Esteem And Self-ConcePt}

\section{A. Theoretical and Methodological Concerns}

Research in this area is proliferating, yet numerous methodological and conceptual problems continue to perplex researchers. At the conceptual level, there is little agreement among researchers on the meaning of the terms "self-esteem" and "self-concept." Some researchers use the terms interchangeably; others draw distinctions. This situation has led to the use of different measures, and thus to different interpretations of results. Nor is there a consensus on how a child's self-concept or self-esteem develops and changes as he or she matures. Cross-cultural studies and impact studies are difficult to interpret if there is no understanding of the developmental processes involved. There is also a need to understand what may be called the dimensions of these constructs and to understand how these dimensions are influenced by cultural patterns.

In this section, the studies reviewed address methodological and substantive issues. One question the studies raise is the extent to which race and class differences in self-esteem are reliable or generalizable. Another important question is whether black students base their general self-esteem on different aspects of their experience than do white students, and whether there is a parallel difference between lower-class and middle-class students in what parts of their experience create their general self-esteem.

Hare studied 210 fifth-graders in an attempt to assess whether children of varying backgrounds differ in their levels of general self-esteem and areaspecific self-esteem (at school, among peers, and at home) ${ }^{27}$ These children had received all of their education in the desegregated schools of Evanston, Illinois. Although the sample contained only limited numbers of middle-class black students and lower-class white children, socioeconomic status was also examined as an influence on these dimensions of self-esteem.

Hare found no racial difference in general self-esteem. However, his research indicated variations in area-specific self-esteem across both race and status lines but no differences according to sex. Whites scored higher than blacks in school self-esteem. In addition, there were significant differences in general, school, and peer self-esteem, according to the student's socioeconomic status, with the higher status students having the higher scores. In this study, home self-esteem was the best predictor of general self-esteem for black children and for blue-collar white children. School self-esteem, the best

27. Hare, Racial and Socioeconomic Variations in Preadolescent Area-Specific and General Self-Esteem, 1 INT'l J. of Interculture Rel., Fall 1977, at 31, 39. 
predictor of general self-esteem for white-collar whites, was not significantly related to general self-esteem for the other groups. In other words, the selfevaluation on the basis of school experiences seems to have had little bearing on the total self-esteem of black children or lower-class children.

Generalization from this study should be cautious-Hare used small samples in some comparisons, and Evanston may be a unique environment in some respects. There is also the possibility of an instrument effect. Hare devised his own instrument for this study, which correlates highly with other recognized instruments such as those developed by Coopersmith ${ }^{28}$ and Rosenberg. ${ }^{29}$ Thus, Hare's scale is measuring a dimension that is widely considered to be self-esteem. ${ }^{30}$

More recently, Hare studied a larger sample of students in Champaign, Illinois. ${ }^{31}$ The schools were desegregated in 1967 by busing. About 90 percent of the fifth graders (513) participated in the study. As in the earlier study, there was no racial difference in general self-esteem among the students. However, unlike Hare's previous study, this one indicated no racial difference on school self-esteem. Significant socioeconomic status differences were found on the home and school subscales but not on the peer subscale. Since the results of the two studies agree on general self-esteem but differ on subscale scores, it appears that the subscale scores are less reliable or more affected by environmental influences like school atmosphere. ${ }^{32}$

A measure of academic self-concept was also included in this study. With socioeconomic status controlled, black children scored significantly higher on self assessments of their ability than did white children. This is surprising, considering the lower performance of black children in comparison to that of white children on the achievement tests reported in this study. The ability of minority high school students to maintain high academic self-concepts despite poor performance was also reported in a study conducted in San Francisco. ${ }^{33}$ Are black children receiving inaccurate information about performance in desegregated schools, or are they ignoring the test scores and teacher evaluations? The phenomenon definitely needs further study.

28. S. Coopersmith, The Antecedents of Self-Esteem (1967).

29. M. Rosenberg, Society and the Adolescent Self-Image (1965).

30. Hare's instrument has a .83 correlation with both the Coopersmith and the Rosenberg scales, which have a .74 correlation with each other.

31. B. R. Hare, Self-Perception and Academic Achievement: Variations in a Desegregated Setting (May 10, 1978) (paper presented at the annual meeting of the American Psychiatric Association).

32. A multitrait-multimethod study of three well-known self-concept measures (the Gordon "How I See Myself Scale," the Piers-Harris "Children's Self-Concept Scale," and the Sears "SelfConcept Inventory") found little evidence that subscales of self-esteem inventories actually measure significantly different facets of self-concept. See Mark \& Winne, Construct Interpretations of Three Self-Concept Inventories, 15 AM. Educ. Research J. 99 (1978).

33. Massey, Scott, \& Dornbusch, Racism without Racists: Institutional Racism in Urban Schools, 7 The Black Scholar, November 1975, at 10, 13. 
In studies of preschool children and elementary school children, there is a need to understand better how a child's self-concept develops. If children show a decline in self-concept between grades one and two, for example does that indicate the impact of the school experience or is it an ordinary developmental progression?

A study done by Cicirelli examined the impact of the school on children's self-concept in comparison to other influences and found that the school had no greater impact on black children's self-concept than it had on the white children's. Cicirelli used the Purdue Self-Concept Scale (PSCS) to study 345 first, second, and third grade children attending inner-city schools in a metropolitan area. ${ }^{34}$ There was a decline in self-concept with grade level, and blacks had a higher self-concept than whites. An analysis of black secondgrade children's scores indicated that the race difference was due to the scores of children whose families were on welfare. These black children had significantly higher self-concepts than did other blacks. Cicirelli suggested that the results may have been due to low evaluative expectations in the welfare environment, increasingly salient black pride, or defensiveness. ${ }^{35}$ The black and white children in this study lived in the same neighborhood and attended the same schools. Therefore, the differences displayed seem to indicate home influences or ethnic influences rather than neighborhood or community influences.

Although it is possible for the school to have different impacts on children of different racial groups even when they are in the same classrooms, this study provides no evidence to support this. Cicirelli states, "[i]t is conceivable that parents and teachers have lower expectations for these [welfare] children than would be the case for their slightly more advantaged peers; however, this should be submitted to empirical test." 36 The low expectations argument is also applicable to Hare's finding that black children have higher self-concepts of their academic ability than whites have, in spite of lower actual achievement. ${ }^{37}$ Defensiveness on the part of blacks who may feel threatened in the testing situation is another possible explanation, but the low expectations hypothesis seems more plausible.

The difficulty of pinning down the meaning of the results of self-concept studies is illustrated further by findings on the influence of age and socioeconomic status across studies. In his cross-sectional study described above, Cicirelli reports that a child's self-concept declines with age. However, McAdoo's longitudinal study, discussed previously, found a significant in-

34. Cicirelli, Relationship of Socioeconomic Status and Ethnicity to Primary Grade Children's SelfConcept, 14 Psrch. IN THE SChOOLS 213 (1977).

35. Id. at 215 .

36. Id.

37. B. R. Hare, supra note 31 , at 13. 
crease from age five to age ten in one sample and no change in another sample that had originally shown high self-esteem. Data on socioeconomic status are equally contradictory. Cicirelli found welfare children to have higher self-concept scores than nonwelfare children; Hare, in two studies, found children of lower socioeconomic status to have lower self-esteem than children of higher socioeconomic status. ${ }^{38}$ It is not clear whether these differences in results are attributable to community influences, instrumentation effects, or design effects (for example, cross-sectional versus longitudinal studies).

\section{B. Impact of Desegregation on Self-Esteem}

Several comprehensive reviews of both published and unpublished studies on the impact of desegregation on children's self-esteem available prior to 1973 have been published. ${ }^{39}$ These reviews have all found a mixed pattern of results-some finding that black students have higher self-concept in desegregated schools, others, that blacks have a higher self-concept in segregated schools. Still other studies have found no significant differences between students in segregated and nonsegregated schools. While this article considers these earlier reviews, little would be gained by going over that ground again. Thus, only studies that have not been reviewed previously will be discussed in the remainder of this section.

Hunt and Hunt, in a re-analysis of the Rosenberg and Simmons data gathered in Baltimore, explored the mediating processes that allow black males to sustain their self-image. Their sample consisted of 690 male students in grades five through twelve. ${ }^{40}$ The researchers used a recent version of the Rosenberg self-esteem scale along with items indicating specific terms of selfdescription (for example, well-behaved, good at sports, hard working in school). There was also a school attachment scale, a measure of sense of control and personal efficacy, and a measure of sex-role identification (conceptions of maleness). The investigation compared students in segregated and desegregated schools. The results indicate that self-esteem of the black males was higher in the segregated schools, while their sense of control and efficacy was higher in the desegregated schools. ${ }^{41}$ The authors present evidence to

38. Cicirelli, supra note 34, at 214; McAdoo, supra note 21, at 57; Hare, supra note 27, at 40; B. R. Hare, supra note 31 , at 11 .

39. See N. St. John, School Desegregation: Outcomes for Children (1975); Epps, Impact of School Desegregation on Aspirations, Self-Concept and Other Aspects of Personality, 39 Law \& ConTEMP. Prob., Spring 1975, at 300; M. Wein Berg, supra note 1 .

40. Hunt \& Hunt, Racial Inequality and Self-Image: Identity Maintenance as Identity Diffusion, 61 Soc. \& Soc. RESEARCH 539, 544 (1977). For a more comprehensive report of the original study, see M. Rosenberg \& R. Simmons, Black and White Self-Esteem: The Urban School Child (1972).

41. Hunt \& Hunt, supra note 40, at 550-51. 
support the hypothesis that a sense of control among these black youths is associated with low school attachment and, therefore, is based on factors unrelated to school. According to the authors, "the findings ... suggest a pattern of self-image maintenance among black boys not so much through rejection of conventional values and institutions and clear substitution of compensatory terms of self-respect, as through distance and diffusion-identification of the dimensions of self with a wide range of both conventional and unconventional terms of identity." 42

Using a different assessment scale, Hughes and Works undertook a study that reached the opposite conclusion from that of the study by Hunt and Hunt. They compared the self-concepts of black teenagers in a predominantly white and a predominantly black high school. ${ }^{43}$ The self-concepts of the black males in the predominantly black school were more positive than those of their counterparts in the predominantly white school, but the racial composition of the school was not associated with the self-esteem of the females. The authors conclude that attendance at a desegregated predominantly white high school may have harmful consequences for the black male. ${ }^{44}$

The Riverside study investigated the self-esteem question only to yield very mixed results. It used a self-report instrument to obtain measures of general and school anxiety, attitudes about others, attitudes about self, and need for school achievement. ${ }^{45}$ Each scale consisted of fifteen items to which students responded yes or no. On all measures administered prior to desegregation, except the need for school achievement scale, Anglo children scored significantly higher than either black or Mexican American students. Minority students differed little from each other, although blacks scored somewhat higher than Mexican Americans. The authors acknowledge that because of a lack of balance between positively worded and negatively worded items on three of the four measures of adjustment, "agreement response bias" 46 may have influenced the outcomes, possibly confounding the results. However, since these results were consistent with studies conducted by other researchers, and since analysis of the intercorrelations among the scales indicated that the agreement response bias was not a primary influence on the scores, ${ }^{47}$ the authors are inclined to view these as genuine racial or ethnic differences.

Controls for socioeconomic status employed in the Riverside study also

42. Id. at 552 (emphasis in original).

43. Hughes \& Works, The Self-Concepts of Black Students in a Predominantly White and in a Predominantly Black High School, 59 Soc. \& Soc. ReSearch 50 (1974).

44. Id. at 53-54.

45. Green, Miller, \& Gerard, Personality Traits and Adjustment, in School Desegregation: A Long-Term Study 170, 173, 190 (H. Gerard \& N. Miller eds. 1975).

46. Id. at 174 .

47. Id. at 175 . 
failed to account for the ethnic differences. ${ }^{48}$ The only significant ethnic group change after desegregation involved younger black children. These children displayed much greater increases in general anxiety than did either Anglo or Mexican American children three years after desegregation. ${ }^{49}$ It should be noted that factor analyses yielded different factor structures for each of the ethnic groups, which suggests that the scales may be measuring different and complex underlying dispositions for each ethnic group. Thus, drawing conclusions about ethnic differences here is a bit hazardous.

Mixed findings also characterize a study conducted by the Department of Research and Evaluation of the Chicago Board of Education. This study compared scores of a control group with those of children who had been bused voluntarily to a desegregated magnet school. ${ }^{50}$ The magnet school children had been selected by lottery from a larger pool of applicants. The control group for this study was randomly selected from lists of applicants who had not been selected to attend the magnet school and therefore were attending neighborhood schools. Some of these neighborhood schools were segregated, while others were interracial.

The comparison with the control group indicated that at every age level (between ages seven and thirteen), control students had higher scores on the self-concept scale. ${ }^{51}$ Comparisons between control and magnet students were not reported separately by racial group. The average scores for black, Hispanic and Anglo-white students attending the magnet school, however, were quite comparable at each age level. While this study does not allow a meaningful comparison of segregated versus desegregated schools by ethnicity, the data taken within each school clearly indicate that in terms of self-esteem, minority children are equal to whites. As Hare points out, "the issues of selfconcept and desegregation are separate." 52 This means that we know too little about self-concept per se to understand how it is affected by desegregation. We do not know enough yet, nor do we have sufficient confidence in our instruments to be confident that the differences revealed in self-esteem have any long range consequences for personal adjustment or for competence as an adult. Differences in self-concept measures make it difficult to generalize among studies. Moreover, there is evidence based on widely used instruments

48. Id. at 176

49. Id. at 180 .

50. Board of Education, City of Chicago, Summary Evaluation of the Disney School 59 (1977) (Dep't of Research and Evaluation mimeographed report). This study was severely criticized by Weinberg because no controls for socioeconomic status were used. This raises questions about comparability of the magnet school and control group students. Weinberg, Is the Disney Magnet School a Success?, in 1 The Center Bulletin, October 1977, at 1 (Center for Equal Education. Northwestern University).

51. The scale used was the Piers-Harris self-concept scale.

52. Hare, Black and White Child Self-Esteem in Social Science: An Overview, $46 \mathrm{~J}$. Negro Educ. $156(1977)$. 
that in biracial or multiracial schools, black and white students of different ages-primary grades through senior high school-have self-esteem scores equal to those of their white schoolmates. However, the factors contributing to these uniform levels of self-esteem may be different for different ethnic groups.

It seems clear that generalizing about the impact of desegregation on selfconcept is unwarranted. As Christmas ${ }^{53}$ and Weinberg ${ }^{54}$ concluded after reviewing the literature, the findings are generally inconclusive. Nevertheless, Weinberg feels that on balance the research suggests that desegregation tends to enhance the self-esteem of minorities. In any case, the research certainly does not support the contention that desegregation is harmful to black selfesteem.

\section{III}

\section{Motivation to Achieve}

Researchers interested in what impact desegregation can have on children's motivation to achieve in school have addressed a wide range of questions. Among these are: When students vary in their level of achievement, is some significant part of that variation due to their motivation to achieve? Do black children from segregated schools become more motivated when they move to desegregated schools? Do a teacher's feelings about racial differences affect how well a student does in his or her classroom?

Biener and Gerard drew heavily on achievement motivation theory in their research design. ${ }^{55}$ The indices of achievement motivation used in their study included: (1) a ring-toss game that yielded measures of goal discrepancy-the difference between expected performance and actual performance, and the number of unusual shifts - such as raising goals after poor performance; (2) an eight-item scale measuring sense of control over the environment; (3) a six-item scale to assess intellectual achievement responsibilities (IAR), which yielded two scores-a "lack of effort" score and a "lack of ability" attribution score; and (4) a measure of the tendency to delay gratification. The authors hypothesized that minority children would improve on these measures after exposure to white classmates in desegregated schools. Their analysis attempted to answer the following questions: (1) Do the measures show the expected differences for age and ethnic group? (2) Do the measures predict school achievement? (3) Is there any indication that desegregation has an impact on behavior related to achievement?

53. Christmas, Self-Concept and Attitudes, in Comparative Studies of Blacks and Whites in THE UNited States 249,268 (1973).

54. M. WEINBERG, supra note 1 , at 159.

55. Biener \& Gerard, Effects of Desegregation on Achievement-Relevant Motivation, in SCHool DEsegregation: A Long-Term Study $121-150$ (H. Gerard \& N. Miller eds. 1975). 
The age and ethnic group responses were about as predicted on the ringtoss goal setting measures and the fate control measures, with older children and Anglo children having more favorable scores. On the measures of intellectual achievement responsibilities (IAR) an age effect was found for "effort" attribution but not for "ability" attribution. There were no ethnic differences on the "effort" attribution measure, but Mexican American children were more likely than either Anglos or blacks to attribute failure to their own ability. Blacks and Anglos did not differ in the evaluation of intellectual achievement responsibilities. The results for delay of gratification were as predicted: older children and Anglos were more likely than younger children or minority children to delay gratification.

To answer the second question regarding the relation of motivation to achievement, a standardized achievement test score, which separated three levels within each ethnic group, was included in an analysis along with school grade, sex, and ethnic group. The goal setting (ring-toss) measure was not related to achievement for any group; fate control was significantly related to achievement for Anglos and Mexican Americans but not for blacks. The "effort" subscale of the intellectual achievement responsibilities measure was not related to achievement. The practice of attributing one's failures to lack of "ability" was associated with low achievement but only among girls. The results for delay of gratification were inconclusive. The authors explain:

In summary, our analysis demonstrates that only a minuscule proportion of the variance in achievement can be accounted for by achievement motivation or at least by our measures of it. We obtained a moderate relationship for fate control and for self-attributions of ability, but the other four variables appeared to be virtually unrelated to achievement scores. ${ }^{56}$

Biener and Gerard then analyzed the impact of desegregation. Their results indicated that there was no effect on goal-setting scores for third and fifth graders, but first-grade minority children performed better after one year of desegregation than did the comparison predesegregation group. However, Biener and Gerard recommend caution in interpreting this result because there were only ten black children in the group that showed improvement. Comparing children who had one year of desegregation experience with those who had three years of desegregation experience reveals that the longer minority children stay in the desegregated school, the more their goal-setting abilities improve. The amount of a child's experience with desegregation did not appear to affect his perception of whether how well he did was controlled by fate. However, after three years of desegregation, "all children were much less likely to delay gratification than were their age mates two years earlier." 57

56. Id. at 139 .

57. Id. at 144 (emphasis in original). 
Perhaps the most important analysis in this study dealt with the effect of teachers' attitudes on children's achievement orientations. On the goal setting measure, it was found that desegregation experience was mediated by the attitudes of teachers. While Anglo children were not affected, third and fourth grade black and Mexican American children in classrooms of teachers who were moderately or highly discriminatory improved their goal setting abilities less than minority children in classrooms of teachers who were less discriminatory did. (The measure of teacher discrimination was derived from the teachers' tendencies to overestimate the achievement inferiority of minority children.) The 1974-75 study of schools receiving Emergency School Aid Act (ESAA) funds ${ }^{58}$ also indicated that teachers' attitudes may affect students' educational expectations. This study found educational expectation to be positively related to school achievement.

The ESAA study of 1975-76 attempted to relate a school's effort to provide minority-oriented cultural enrichment materials and activities to its success in raising student achievement. ${ }^{59}$ The rationale is based on the assumption that such cultural enrichment programs lead to improved self-images among minority children, and that improved self-images are related to improved academic achievement. A positive relationship between cultural enrichment activities and minority achievement scores was found, but there was no direct measure of self-image. Other research found no significant effect on the self-esteem or grade point averages of participants in black studies programs. ${ }^{60}$ However, the ESAA impact studies did find support for the belief that there is a positive relationship between a student's sense of control and his or her achievement (for basic secondary school students). ${ }^{61}$

While these data do not provide direct evidence that desegregation enhances minority students' sense of control, or that a strong sense of control causes high achievement, they do suggest that there is a correlation between a child's sense of control and his level of achievement. Evidence gathered by other researchers indicates that the sense of control among minority students

58. J. Wellisch, A. Marcus, A. MacQueen, \& G. Duck, An In-Depth Study of Emergency School Aid Act (ESAA) Schools: 1974-75 (July 1976) (report for System Development Corporation).

59. J. Wellisch, An In-Depth Study of Emergency School Aid Act (ESAA) Schools: 1975-76 (March 1977) (report for System Development Corporation).

60. See, e.g., Carey \& Allen, Black Studies: Expectation and Impact on Self-Esteem and Academic Performance, 57 Soc. ScI. Q. 811, 816 (1977).

61. J. Coulson, D. Ozenne, N. Van Gelder, D. Inuzuka, C. Bradford, \& W. Doherty, The First Year of Emergency School Aid Act (ESAA) Implementation (September 1975) (ERIC Document No. 177 229); J. Coulson, D. Ozenne, C. Bradford, W. Doherty, G. Duck, J. Hemenway, \& N. Van Gelder, The Second Year of Emergency School Aid Act (ESAA) Implementation (July 1976) (ERIC Document No. 133 362); J. Coulson, D. Ozenne, S. Hanes, C. Bradford, W. Doherty, G. Duck, \& J. Hemenway, The Third Year of Emergency School Aid Act (ESAA) Implementation (March 1977) (all under contract from System Development Corporation). 
is greater in desegregated schools than in segregated schools. ${ }^{62}$ Considering these findings, researchers are warranted in continuing research on students' sense of control.

Hare's study, in addition to looking at self-esteem and self-concept of ability, looked at ethnic differences in children's sense of control and achievement orientation. ${ }^{63}$ Sense of control was measured by the three item scale used in the Coleman Report. ${ }^{64}$ Achievement orientation was measured by a thirteen item self-report scale that incorporated the achievement values described by Rosen. ${ }^{65}$

In the interracial school system studied by Hare, whites scored significantly higher than blacks on both measures at the fifth-grade level. There was also a significant socioeconomic status effect independent of the race effect. It is quite possible that these measures reflect cultural differences of perception as well as actual differences in the way youngsters in the different race and class groups experience day-to-day life.

One important consideration is the question of what the results mean for educational policy. If these scores reflect attitudes that are necessary for achievement, then schools should be working to eliminate group differences; the data show that these schools had not succeeded. Another consideration is one suggested by Ramirez and Price-Williams: Is it valid to apply an AngloAmerican definition of individualistic achievement motivation to groups that place greater emphasis on group or family expressions of achievement and approval?66 This tradition of group-related achievement may have relevance for organization of classroom instruction in desegregated schools as a means of increasing motivation and achievement among minority children. ${ }^{67}$

Beerling investigated aspirations and levels of motivation among black and white students at an interracial high school in Joliet, Illinois. ${ }^{68}$ Levels of occupational and educational aspirations did not differ for blacks and whites, even though achievement was higher for whites. However, blacks scored lower than whites on an achievement orientation (values) scale and were more likely to feel that their future opportunities were limited. Although blacks and whites did not differ in average scores on a scale measuring self-concept of ability,

62. Hunt \& Hunt, supra note 40 , at 551.

63. Hare, supra note 31 , at 10 .

64. J. Coleman, E. Campbell, C. Hobson, J. McPartland, A. Mood, f. Weinffld, \& R. York, Equality of Educational Opportunity (1966).

65. Rosen, The Achievement Syndrome: A Psychocultural Dimension of Social Stratification, in Motives in Fantasy, Action, And Society 495 (J. Atkinson ed. 1958).

66. Ramirez \& Price-Williams, Achievement Motivation in Children of Three Ethnic Groups in the United States, 7 J. Cross-Cultural Psych. 49 (1976).

67. See, e.g., D. Devries \& I. Mescon, Team-Games Tournament: An Effective Task and Reward Structure in Elementary Grades (Johns Hopkins University Center for Social Organization of Schools Report 189, 1975).

68. J. Beerling, Black Goals-White Goals: A Study of the Effects of Personality Characteristics on Aspirations (1976) (unpublished doctoral dissertation, The University of Chicago). 
whites were more likely to be found in the top third of the self-reported ability distribution.

In the school studied by Beerling, a weighted system of grading is used in which it is possible for students with identical grades to compile different grade point averages. Honor classes are given the highest weighting, followed by regular, basic, remedial, and special education classes, in that order. Thus, it is not surprising that the percentage distributions for self-concept of academic ability do not appear to reflect the distributions for grade point averages. The tracking system results both in segregated classes within the high school and inaccurate feedback about academic achievement for black students.

Ruhland and Feld studied the development of achievement motivation in black and white children in two working-class elementary schools. ${ }^{69}$ One school was 33 percent black, the other, 85 percent black. The results indicated that the black and white children did not differ in "autonomous" achievement motivation, which is learned prior to school age. However, white students scored significantly higher on social comparison motivation, which is acquired during the elementary school years. ${ }^{70}$ As Ruhland and Feld assert, the classroom is a major source of information about how one's ability compares to that of one's peers. If teachers have low expectations for minority students, or if they provide other inaccurate feedback, they may subvert the process of developing effective social comparison skills. Also, communication of low expectations could foster school anxiety and an avoidance of social comparison situations in the school setting. It is also possible that since this form of motivation to achieve stresses an individualistic perspective, it may be in conflict with cultural styles of blacks and other minorities that stress family or group oriented achievement and discourage comparison with peers.

\section{Conclusion}

A previous review of research by this author concluded that there is no need to assume that blacks suffer from low self-esteem or low aspirations, whether they attend segregated or desegregated schools. This review of the more recent research suggests that there is no need to make any basic changes in the previous conclusions, although a few qualifications might be added.

It is probable that the developmental dynamics of self-identity, self-esteem,

69. Ruhland \& Feld, The Development of Achievement Motivation in Black and White Children, 48 Child Dev. 1362 (1977).

70. Id. at 1366. Autonomous standards define excellence in relation to one's own past performance. Social comparison standards are based on comparisons between one's own performance and that of others. The findings on autonomous motivation provide support for Banks's and McQuater's contention that the roots of low achievement in blacks are not located in family and early socialization experiences. See Banks and McQuater. Achievement Motivation and Black Children, 4 IRCD Bull.. Fall 1976, at 6. 
aspiration, and motivation are different for each ethnic group and are further related to socioeconomic status. It is also probable that desegregation versus segregation is too gross a comparison. Experiences vary within schools and classrooms to such an extent that these variations in settings-both quantitative and qualitative-must be included in the research design. For example, Felice and Richardson report that dropout rates for bused minority students are similar to but slightly higher than those for nonbused minority students. ${ }^{71}$ This general finding is of less importance, however, than the fact that dropout rates for bused students are strongly affected by the socioeconomic composition of the students and by teacher expectations at the receiving schools. Felice and Richardson explain, "Desegregation produces a positive benefit for this most crucial dimension of minority student educational accomplishment, when the school to which the minority student is bused is one where teachers' expectations are positive and supportive." 72

This article has examined the conceptual and methodological concerns involved in understanding the impact of desegregation on minority students. Because of the limits of existing theory and research on the fundamental questions of developments in personality that may be influenced by desegregation and thus affect the success of desegregation at both the individual and group levels, the article has not focused extensively on comparisons between segregated and desegregated schools. Instead, the broader developmental questions as well as research issues concerning both assessment and interpretation have been examined. Three general conclusions seem important at this stage. First, more careful attention must be given to the nature of the phenomena being studied-the personality characteristics themselves. Second, what goes on within schools and classrooms should be of greatest concern rather than the simple segregation versus desegregation comparisons. Finally, cultural differences must be taken into consideration as we evaluate attitudes and motivation.

71. Felice \& Richardson, The Effects of Busing and School Desegregation on Minority Student Dropout Rates, 70 J. Educ. ReSEARCH, May-June 1977.

72. Id. at 242 . 